\title{
Glycaemic index and glycaemic load values of commercially available products in the UK
}

\author{
C. Jeya K. Henry ${ }^{1}$, Helen J. Lightowler ${ }^{1}$, Caroline M. Strik ${ }^{1}$, Hamish Renton ${ }^{2}$ and Simon Hails ${ }^{3}$ \\ ${ }^{1}$ Nutrition and Food Science Group, School of Biological and Molecular Sciences, Oxford Brookes University, Gipsy Lane Campus, \\ Headington, Oxford OX3 OBP, UK \\ ${ }^{2}$ Tesco Stores Limited, Tesco House, Delamare Road, Cheshunt, Hertfordshire EN8 9SL, UK \\ ${ }^{3}$ Reading Scientific Services Limited, The Lord Zuckerman Research Centre, Whiteknights Campus, Reading RG6 6LA, UK
}

(Received 10 March 2005 - Revised 18 July 2005 - Accepted 5 August 2005)

\begin{abstract}
The objective of this paper is to provide glycaemic index (GI) and glycaemic load (GL) values for a variety of foods that are commercially available in the UK and to compare these with previously published values. Fasted subjects were given isoglucidic ( $50 \mathrm{or} 25 \mathrm{~g}$ carbohydrate) servings of a glucose reference at least two to three times, and test foods once, on separate occasions. For each test food, tests were repeated in at least eight subjects. Capillary blood glucose was measured via finger-prick samples in fasting subjects $(0 \mathrm{~min})$ and at 15, 30, 45, 60, 90 and $120 \mathrm{~min}$ after the consumption of each test food. The GI of each test food was calculated geometrically by expressing the incremental area under the blood glucose response curve (IAUC) of each test food as a percentage of each subject's average IAUC for the reference food. GL was calculated as the product of the test food's GI and the amount of available carbohydrate in a reference serving size. The majority of GI values of foods tested in the current study compare well with previously published values. More importantly, our data set provides GI values of several foods previously untested and presents values for foods produced commercially in the UK.
\end{abstract}

Glycaemic index: Glycaemic load

The glycaemic index (GI), first introduced in 1981 (Jenkins et al. 1981), is a classification of the blood glucose-raising potential of carbohydrate foods. It is defined as the incremental area under the blood glucose curve (IAUC) of a $50 \mathrm{~g}$ carbohydrate portion of a test food expressed as a percentage of the response to $50 \mathrm{~g}$ carbohydrate of a reference food taken by the same subject, on a different day (Food and Agriculture Organization/World Health Organization, 1998).

Since the concept of GI was first introduced, many studies have investigated the potential health benefits of low-GI foods. The GI of foods may have important implications for the prevention and treatment of the major causes of morbidity and mortality in Western countries, including type 2 diabetes, CHD and obesity. Today, there is an important body of evidence to support the therapeutic potential of low-GI diets, not only in diabetes (Björck et al. 1994; Frost et al. 1994; Gilbertson et al. 2001), but also in subjects with hyperlipidaemia (Jenkins et al. 1987a). In addition, low-GI foods have been associated with prolonged endurance during physical activity (Thomas et al. 1991), improved insulin sensitivity (Frost et al. 1998), increased colonic fermentation (Jenkins et al. 1987b; Wolever et al. 1992) and appetite regulation (Warren et al. 2003). More recent data support the preventive potential of a low-GI diet against the development of type 2 diabetes and CVD (Salmeron et al. 1997a,b; Frost et al. 1999; Meyer et al. 2000).
The use of GI for the classification of carbohydrate-rich foods has been endorsed by the FAO/WHO, who recommended that the GI of foods be considered together with information about food composition to guide food choices (Food and Agriculture Organization/ World Health Organization, 1998). GI values represent the glycaemic response of isoglucidic foods, and therefore are not always representative of the glycaemic effect of a typical serving of that food. To quantify the overall glycaemic effect of a standard portion of food, the concept of glycaemic load (GL) was introduced (Salmeron et al. 1997a,b). The GL of a typical serving of food is the product of the amount of available carbohydrate in that serving and the GI of the food, divided by 100 . It is often necessary to consider the GL alongside GI values, especially when the carbohydrate content of the food is relatively small. For example, broad beans have been shown to have a high GI but because they contain very little carbohydrate they have a low GL (Foster-Powell et al. 2002).

The GI of foods varies significantly due to factors such as particle size, cooking and food processing, other food components (e.g. fat, protein, dietary fibre) and starch structure (Björck et al. 1994). Consequently, there is often considerable variation in the GI of the same food produced in different countries or by different manufacturers.

Publication of reliably measured GI and GL values is needed to prevent unnecessary repetition of work and improve work in this exciting area. The largest table of GI and GL values published to date lists 750 different items across a range of globally produced 
food groups and brands (Foster-Powell et al. 2002). The table represents a valuable and well-cited resource for researchers and clinicians and is likely to have been instrumental in sparking the explosion of research in this area. However, the vast majority of published GI values are Australasian or Canadian in origin, with some Danish, French and Swedish values. There is currently a paucity of published GI values for foods produced in the UK. The aim of the current work is to provide reliable values of GI and GL for a range of foods commercially available in the UK. This initiative was the outcome of the Tesco Stores Limited GI labelling programme introduced in June 2004.

\section{Methods}

\section{Subjects}

A total of 189 (seventy male, 119 female) healthy subjects were recruited to take part in the study. Subjects were recruited through posters distributed at Oxford Brookes University ( $n$ 112) and the University of Reading ( $n$ 77). Exclusion criteria were as follows: age $<18$ or $>55$ years; BMI $\geq 25 \mathrm{~kg} / \mathrm{m}^{2}$; fasting blood glucose value $>6.1 \mathrm{mmol} / \mathrm{l}$. Ethical approval for the study was obtained from the respective university's Research Ethics Committee. Subjects were given full details of the study protocol and the opportunity to ask questions. All subjects gave written informed consent prior to participation.

All anthropometric measurements were made in the fasting state. Height was recorded to the nearest centimetre using a stadiometer (Seca Ltd, Birmingham, UK), with subjects standing erect and without shoes. Body weight was recorded to the nearest $0 \cdot 1 \mathrm{~kg}$ using the Tanita BC-418 MA (Tanita UK Ltd, Yiewsley, Middx, UK), with subjects wearing light clothing and no shoes. BMI was calculated using the standard formula: weight $(\mathrm{kg}) /$ height $(\mathrm{m})^{2}$. Characteristics of the subjects are shown in Table 1.

\section{Study protocol}

The protocol used was adapted from that described by Wolever $\mathrm{et}$ al. (1991) and is in line with procedures recommended by the Food and Agriculture Organization/World Health Organization (1998). For each test food, tests were repeated in a minimum of eight subjects. Subjects tested between two and twelve test foods. On the day prior to a test, subjects were asked to restrict their intake of alcohol and caffeine-containing drinks and to restrict their participation in intense physical activity (e.g. long periods at the gym, excessive swimming, running, aerobics). Subjects were also told not to eat or drink after 21.00 hours the night before a test, although water was allowed in moderation.

\section{Test foods}

A number of different foods were tested, including breads, cereals, pasta, basmati rice varieties, pulses, ready-to-eat meals and

Table 1. Characteristics of study population

(Mean values and standard deviations for 189 subjects)

\begin{tabular}{lcc}
\hline & Mean & SD \\
\hline Age (years) & 36.5 & 11.8 \\
Height $(\mathrm{m})$ & 1.70 & 0.10 \\
Weight $(\mathrm{kg})$ & 68.3 & 14.3 \\
BMl $\left(\mathrm{kg} / \mathrm{m}^{2}\right)$ & 23.4 & 4.3 \\
\hline
\end{tabular}

low-fat yoghurts. These foods represent a diverse range of commercial foods commonly consumed in the UK. All foods were provided by Tesco Stores Limited and were originally tested for GI labelling purposes. All foods were tested in equivalent available carbohydrate amounts (50 or $25 \mathrm{~g}$ ) and compared with a reference food (glucose). Available carbohydrate values were provided by the manufacturer. Most foods were tested against $50 \mathrm{~g}$ available carbohydrate; however, if the serving size was considered too large to consume comfortably, foods were tested against $25 \mathrm{~g}$ available carbohydrate (Brouns et al. 2005).

Where required, foods were prepared following the manufacturer's instructions. All breakfast cereals were consumed dry with the exception of the porridge products, which were made with water and cooked in the microwave according to the manufacturer's instructions. Unsalted water was used when soaking or boiling foods was necessary.

In accordance with FAO/WHO recommendations, subjects tested each test food once and the reference food two or three times in random order on separate days, with at least a $1 \mathrm{~d}$ gap between measurements to minimise carry-over effects (Food and Agriculture Organization/World Health Organization, 1998). Subjects were studied in the morning after a $12 \mathrm{~h}$ overnight fast. Subjects consumed the reference/test food at a comfortable pace, within $15 \mathrm{~min}$. The test foods and reference food were served with $200 \mathrm{ml}$ water. A further $200 \mathrm{ml}$ water was given during the subsequent $2 \mathrm{~h}$. Subjects were encouraged to keep physical activity to a minimum during the testing.

\section{Blood glucose measurements}

A qualified technician performed blood glucose measurements. A fasting blood sample was taken at $0 \mathrm{~min}$ and the reference/test food was consumed immediately after this. Further blood samples were taken at 15, 30, 45, 60, 90 and 120 min after starting to eat.

Blood was obtained by finger-prick using the Glucolet 2 multipatient lancing system (Bayer HealthCare, Newbury, Berks., UK). Recent reports suggest that capillary rather than venous blood sampling is preferred for reliable GI testing (Food and Agriculture Organization/World Health Organization, 1998; Wolever, 2003; Brouns et al. 2005). Prior to a finger-prick, subjects were encouraged to warm their hand to increase blood flow. Fingers were not squeezed to extract blood from the fingertip in order to minimise plasma dilution. Blood glucose was measured using Ascensia Contour $^{\circledR}$ automatic blood glucose meters (Bayer HealthCare). The blood glucose meters were calibrated daily using control solutions from the manufacturer and were also regularly calibrated against a clinical dry chemistry analyser (Reflotron ${ }^{\circledR}$ Plus; Roche, Welwyn Garden City, Herts., UK) and the HemoCue Glucose $201+$ analyser (HemoCue ${ }^{\circledR}$ Ltd., Dronfield, Derbyshire, UK).

Fig. 1 shows the Pearson regression and Bland-Altman analyses for a random selection of 140 blood samples simultaneously measured using the Ascensia Contour ${ }^{\circledR}$ and the HemoCue Glucose $201+$ analyser. There was a very strong correlation ( $r$ 0.980, $P<0.001$ ) and good agreement (mean difference $-0.2 \mathrm{mmol} ; 95 \% \mathrm{CI}-0.3,-0.2$; limits of agreement -0.80 , $0 \cdot 32$ ) between blood glucose measurements using the automatic analyser and the HemoCue analyser.

\section{Calculation of glycaemic index and glycaemic load}

The IAUC, ignoring the area beneath the baseline, was calculated geometrically for each food (Food and Agriculture Organization/ 


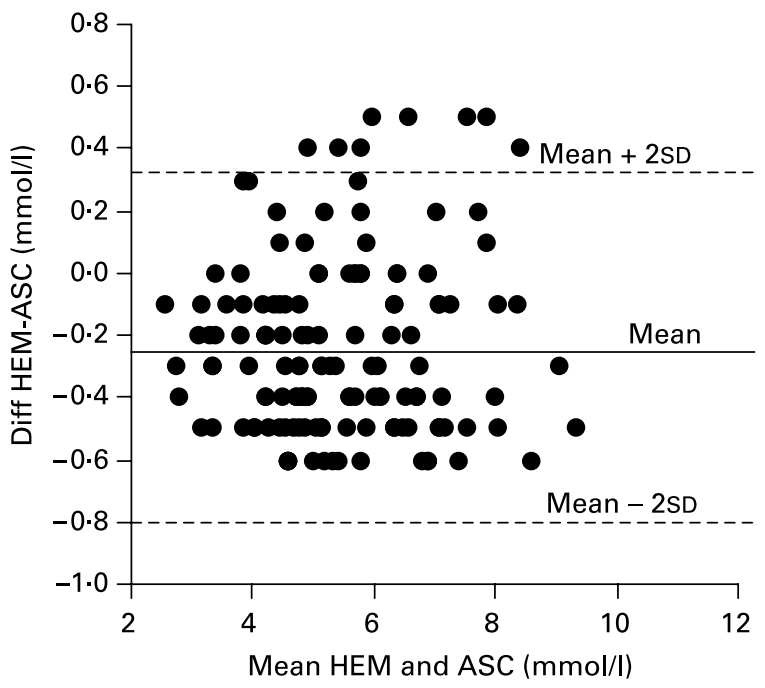

Fig. 1. Bland-Altman analyses of blood glucose measurements between the Ascensia Contour ${ }^{\circledR}$ (ASC) and HemoCue 201+ analyser (HEM). For details of subjects and procedures, see p. 923.

World Health Organization, 1998). The mean, standard deviation and $\mathrm{CV}$ of the IAUC of each subject's repeated reference food were calculated. The IAUC for each test food eaten by each subject was expressed as a percentage of the mean IAUC for the reference food eaten by the same subject: GI = (IAUC test food/IAUC reference food) $\times 100$. The GI of each test food was taken as the mean for the whole group.

The GL of a specific serving of each food was calculated using the following equation: GL $=(\mathrm{GI}$ of test food $\times$ available carbohydrate in a serving of test food $[\mathrm{g}] / 1 / 100$.

Serving size of each test food was taken from manufacturers' information or where this was not available from a well-recognised book of standard food portion sizes (Ministry of Agriculture, Fisheries and Food, 1993).

\section{Statistical analysis}

Statistical analysis was performed using the Statistical Product and Service Solutions software (SPSS version 11.0.1; Chicago, IL, USA). To examine the correlation and agreement between the automatic analyser and the HemoCue Glucose 201+ analyser, the Pearson's correlation coefficient and the method of Bland and Altman (1986) were used. Levels of inter- and intra-individual variation of the three standard (glucose) tests were assessed by determining the $\mathrm{CV} \%$. Spearman's correlation coefficient, $\rho$, was used to assess the relationship between GI values and nutrient content of the test foods. Statistical significance was set at $P<0.05$.

\section{Results}

The mean $\mathrm{CV}$ of glycaemic responses to the three standard tests for the 189 subjects was $26 \%$. The inter-individual CV in glycaemic response to the 25 and $50 \mathrm{~g}$ standard tests was $42 \%$ and $38 \%$, respectively. These values are consistent with previously reported data (Wolever, 1990).

The GI and GL values for all tested foods are given in Table 1. Values are given as means with their standard errors. For practical application, GI values are often grouped into categories as producing a low, medium or high glycaemic response: low $\leq 55$; medium 56-69 inclusive; high $\geq 70$ (Brand-Miller et al. 2003). Both the bread and cereals produced a wide range of GI values with some producing low (e.g. malted wheat bread, bran flakes), some medium (e.g. white pitta bread, Value muesli) and some high (e.g. Value fruit loaf, sultana bran). All pasta products fell into the low-GI category, while the basmati rice was low to medium. All dried pulses and dairy products had low GI values, as did the majority of ready-to-eat meals and dried fruits and nuts tested.

There was no strong relationship between GI value and macronutrient content per $100 \mathrm{~g}$ of the test foods (Fig. 2): energy intake (Spearman's $\rho 0.447 ; P<0.001)$; percentage of energy from protein (Spearman's $\rho-0.441 ; P<0.001$ ); percentage of energy from fat (Spearman's $\rho-0.005 ; P=0.960$ ).
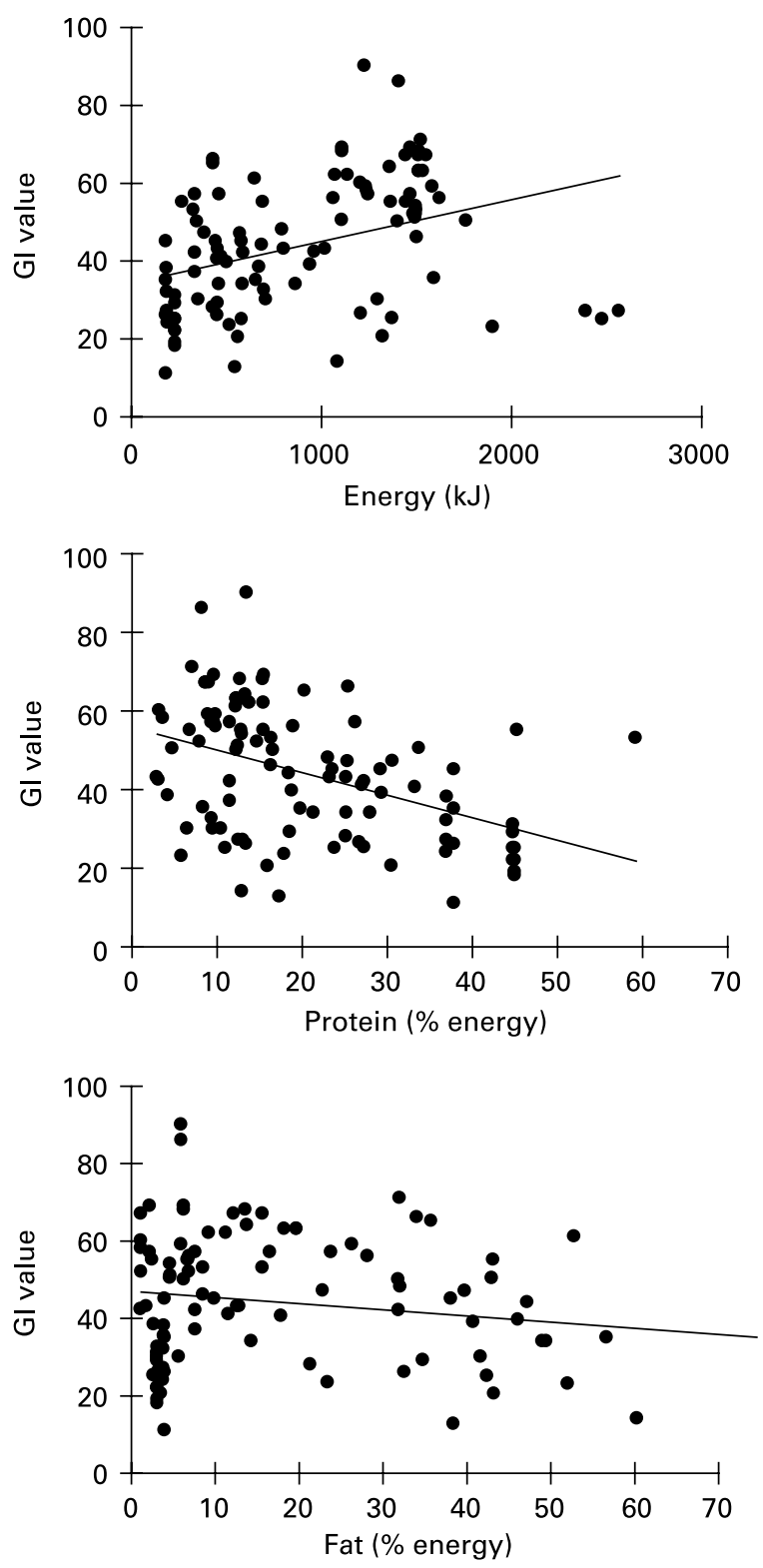

Fig. 2. Relationship between glycaemic index (GI) values and energy, protein and fat content per $100 \mathrm{~g}$ test food. For details of subjects and procedures, see p. 923. 


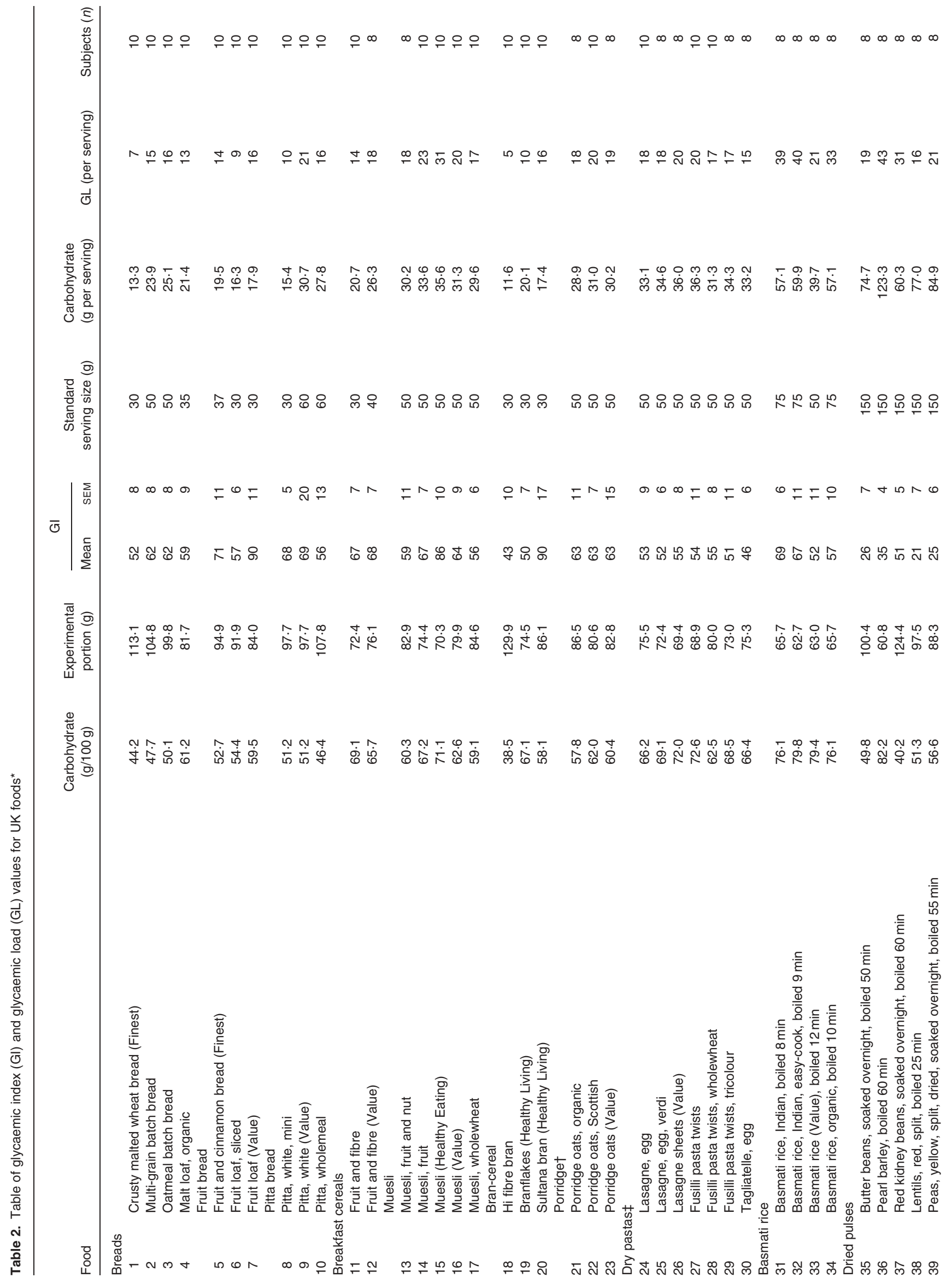




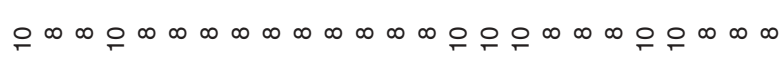

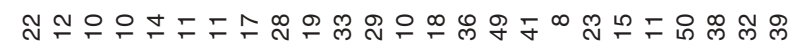

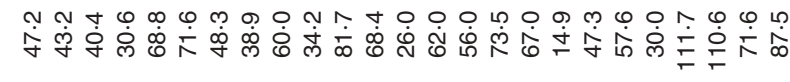

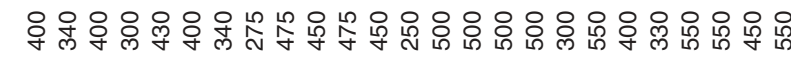

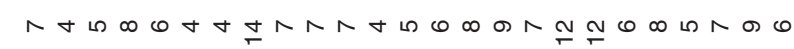

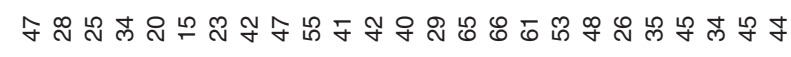

hrow

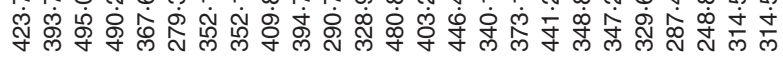

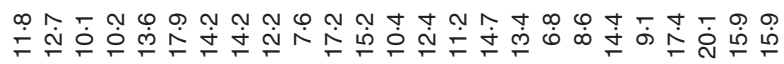

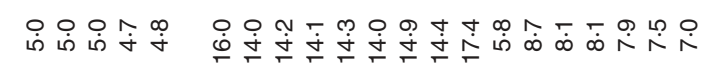

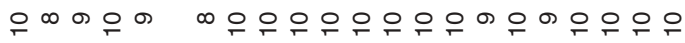

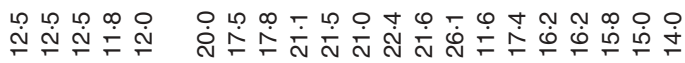

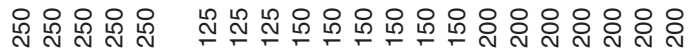

$\llcorner 0 \infty$ 우

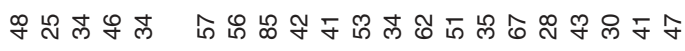

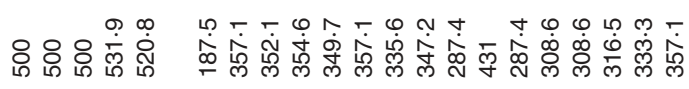

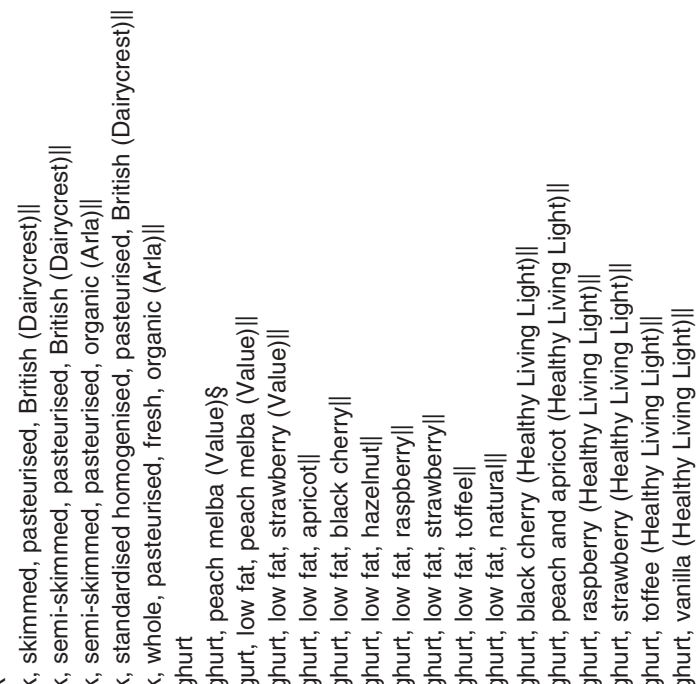

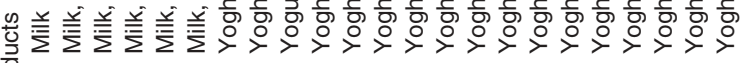

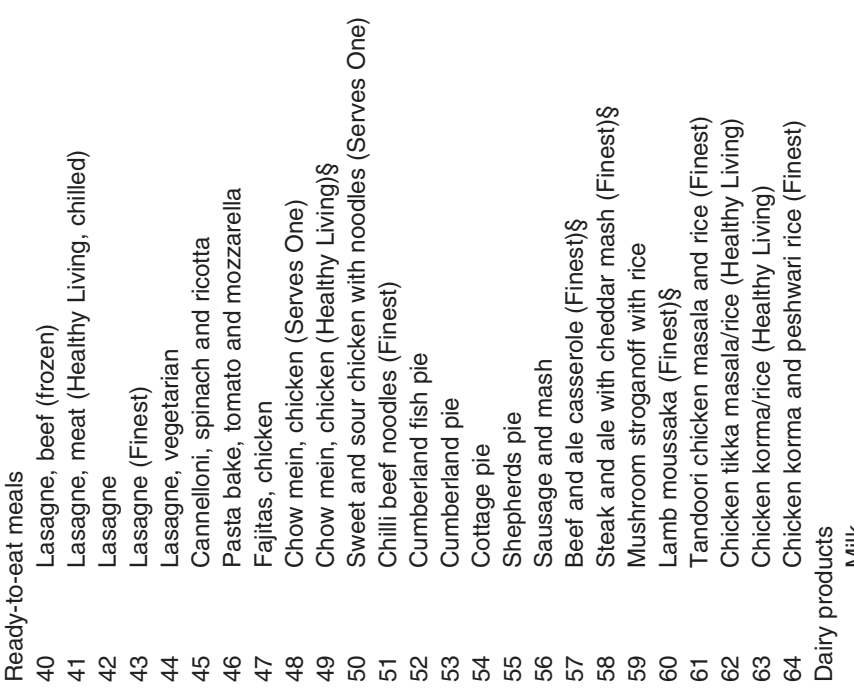




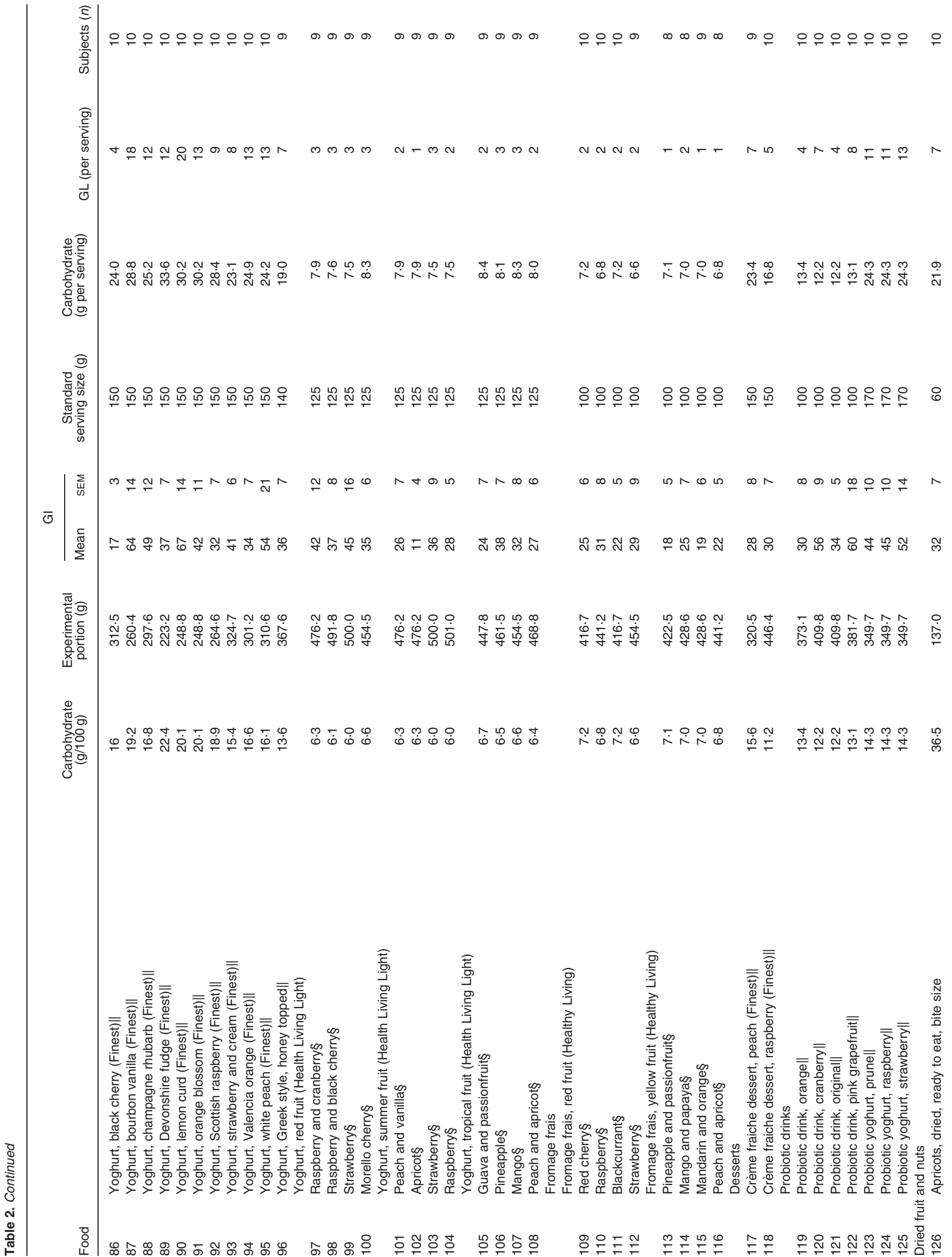




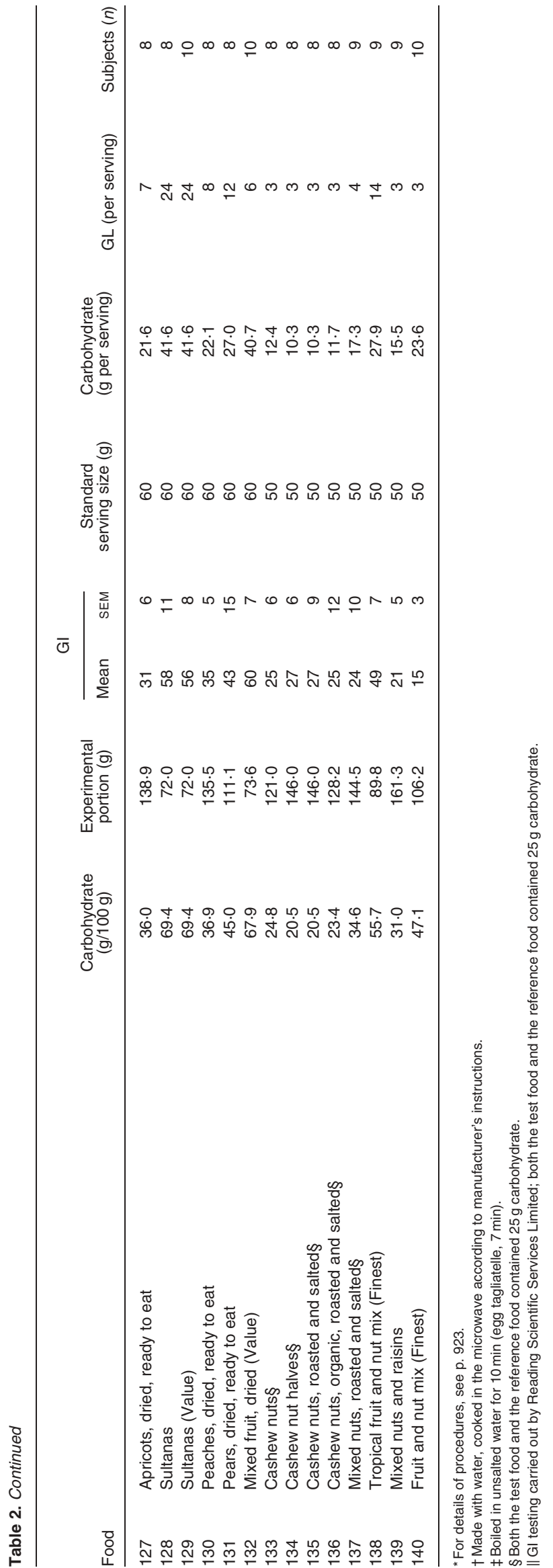




\section{Discussion}

The majority of GI values of foods tested in the current study compare well with previously published values (Foster-Powell et al. 2002). For example, in healthy subjects, the GI values for dried apricots (30), high-fibre bran (42), basmati rice (58), butter beans (28) and salted cashew nuts (22) reported in the international table of GI values (Foster-Powell et al. 2002) are similar to those shown in Table 2.

Small differences of less than 10-15 units in GI values are within the error associated with the measurement of GI (Wolever et al. 1991; Foster-Powell et al. 2002), however, there were a few values that were notably different to those of Foster-Powell et al. (2002). The high GI value (90 (SEM 11)) obtained for Value fruit loaf was unexpected as adding a lowGI ingredient such as dried fruit to a bread would be expected to lower its GI. The value obtained for bran flakes in the present study was considerably lower than the value published in 2002 by Foster-Powell et al. (absolute GI value 50 compared with 74). This highlights the need to test foods in the country of consumption if possible, as the processing conditions and the raw ingredients used may have a significant impact on GI. The GI of wholemeal pitta had not been published previously. Both the white and the wholemeal pitta fell into the medium GI category.

There are several factors that may alter the GI of a food, including the presence of other macronutrients such as fat and protein. The presence of large amounts of protein or fat may significantly reduce the glycaemic response by increasing insulin secretion and slowing gastric emptying (Collier et al. 1984; Nuttall et al. 1984). However, in the present study, protein showed only a moderate negative association with GI value and there was no association between GI value and fat content per $100 \mathrm{~g}$ of the test foods or per serving size tested. This reinforces the findings of Wolever et al. (1994) that the amount of protein or fat found in commonly consumed foods does not significantly affect glycaemic response.

With the increasing consumption of composite, ready-to-eat, meals in our society the current GI table will enable consumers and researchers alike to select low-GI foods for their respective needs. The majority of ready-to-eat meals produced low GI values. Only those products containing a high proportion of mashed potato, i.e. cottage pie, shepherds pie and sausage and mash, produced medium GI values.

The application of the GI to mixed meals is based on the assumption that the glycaemic response to different foods will be equally influenced by co-ingestion of protein or fat. However, Gulliford et al. (1989) found that the glycaemic response to two carbohydrate-rich foods was not equally modified by the co-ingestion of protein and fat. Therefore, it is important to test the GI of composite meals, instead of trying to calculate the GI from GI tables (Flint et al. 2004).

In summary, Table 2 provides reliable values of GI and GL for foods consumed in the UK. In addition to this, our data set provides GI values of several foods previously untested. This information will help prevent unnecessary replication of GI testing and will aid further research into the application of GI.

\section{Acknowledgements}

We would like to thank Angela Hoffman of Tesco Stores Limited for her continued support. We would also like to acknowledge the contributions of Freya Kendall and Padideh Sabeti of Oxford
Brookes University and Jane Staniforth of Reading Scientific Services Limited.

\section{References}

Björck I, Granfeldt Y, Liljeberg H, Tovar J \& Asp NG (1994) Food properties affecting the digestion and absorption of carbohydrates. Am J Clin Nutr 59, S699-S705.

Bland JM \& Altman DG (1986) Statistical methods for assessing agreement between two methods of clinical measurement. Lancet 1, 307-310.

Brand-Miller J, Foster-Powell K \& Colagiuri S (2003) The New Glucose Revolution. New York: Marlowe and Company.

Brouns F, Bjorck I, Frayn KN, Gibbs AL, Lang V, Slama G \& Wolever TMS (2005) Glycaemic index methodology. Nutr Res Rev 18, $145-171$.

Collier G, McLean A \& O'Dea K (1984) Effect of co-ingestion of fat on the metabolic responses to slowly and rapidly absorbed carbohydrates. Diabetologia 26, 50-54.

Food and Agriculture Organization/World Health Organization (1998) Carbohydrates in Human Nutrition. Report of a Joint FAO/WHO Expert Consultation. Rome: FAO.

Flint A, Moller BK, Raben A, Pedersen D, Tetens I, Holst JJ \& Astrup A (2004) The use of glycaemic index tables to predict glycaemic index of composite breakfast meals. Br J Nutr 91, 979-989.

Foster-Powell K, Holt SHA \& Brand-Miller JC (2002) International table of glycemic index and glycaemic load values: 2002. Am J Clin Nutr 76, 5-56.

Frost G, Wilding J \& Beecham J (1994) Dietary advice based on the glycaemic index improves dietary profile and metabolic control in Type 2 diabetic patients. Diabet Med 11, 397-401.

Frost G, Leeds AA, Dore CJ, Madeiros S, Brading S \& Dornhorst A (1999) Glycaemic index as a determinant of serum HDL-cholesterol concentration. Lancet 353, 1045-1048.

Frost G, Leeds A, Trew G, Margara R \& Dornhorst A (1998) Insulin sensitivity in women at risk of coronary heart disease and the effect of a low glycemic diet. Metabolism 47, 1245-1251.

Gilbertson HR, Brand-Miller JC, Thorburn AW, Evans S, Chondros P \& Werther GA (2001) The effect of flexible low glycemic index dietary advice versus measured carbohydrate exchange diets on glycemic control in children with type 1 diabetes. Diabetes Care 24, $1137-1143$

Gulliford MC, Bicknell EJ \& Scarpello JH (1989) Differential effect of protein and fat ingestion on blood glucose responses to high- and low-glycemic-index carbohydrates in noninsulin-dependent diabetic subjects. Am J Clin Nutr 50, 773-777.

Ministry of Agriculture, Fisheries and Food (1993) Food Portion Sizes, 2nd ed. London: H.M. Stationery Office.

Jenkins DJA, Wolever TMS, Collier GR, Ocana A, Rao AV, Buckley G, Lam Y, Mayer A \& Thompson LU (1987b) Metabolic effects of a low glycemic index diet. Am J Clin Nutr 46, 968-975.

Jenkins DJA, Wolever TMS, Kalmusky J, et al. (1987a) Low-glycemic index diet in hyperlipidemia: use of traditional starchy foods. Am J Clin Nutr 46, 66-71.

Jenkins DJA, Wolever TMS, Taylor RH, Barker H, Fielden H, Baldwin JM, Bowling AC, Newman HC, Jenkins AL \& Goff DV (1981) Glycemic index of foods: a physiological basis for carbohydrate exchange. Am J Clin Nutr 34, 362-366

Meyer KA, Kushi LH, Jacobs DR, Slavin J, Sellers TA \& Folsom AR (2000) Carbohydrates, dietary fiber, and incident type 2 diabetes in older women. Am J Clin Nutr 71, 921-930.

Nuttall FQ, Mooradian AD, Gannon MC, Billington C \& Krezowski P (1984) Effect of protein ingestion on the glucose and insulin response to a standardized oral glucose load. Diabetes Care 7, 465-470.

Salmeron J, Ascherio A, Rimm EB, Colditz GA, Spiegelman D, Jenkins DJ, Stampfer MJ, Wing AL \& Willet EC (1997a) Dietary fiber, glycaemic load, and risk of NIDDM in men. Diabetes Care 20, $545-550$. 
Salmeron J, Manson JE, Stampfer MJ, Colditz GA, Wing AL \& Willet EC (1997b) Dietary fiber, glycaemic load, and risk of non-insulin-dependent diabetes mellitus in women. JAMA 277, 472-477.

Thomas DE, Brotherhood JR \& Brand JC (1991) Carbohydrate feeding before exercise: effect of glycemic index. Int J Sports Med 12, $180-186$.

Warren JM, Henry CJK \& Simonite P (2003) Low glycemic index breakfasts and reduced food intake in preadolescent children. Pediatrics 112, e414-e419.

Wolever TMS (1990) The glycemic index. World Rev Nutr Diet 62, $120-185$.
Wolever TMS (2003) Carbohydrate and the regulation of blood glucose and metabolism. Nutr Rev 61, S40-S48.

Wolever TMS, Jenkins DJA, Jenkins AL \& Josse RG (1991) The glycemic index: methodology and clinical implications. Am J Clin Nutr 54, 846-854.

Wolever TMS, Jenkins DJA, Vuksan V, Jenkins AL, Buckley GC, Wong GS \& Josse RG (1992) Beneficial effect of a low glycemic index diet in Type 2 diabetes. Diabet Med 9, 451-458.

Wolever TMS, Katzmanrelle L, Jenkins AL, Vuksan V, Josse RG \& Jenkins DJA (1994) Glycemic index of 102 complex carbohydrate foods in patients with diabetes. Nutr Res 14, 651-669. 